\title{
EDITORIAL
}

\section{Retrospective and New Initiatives for 2013}

In 2010, Frontiers of Education in China underwent a complete change of direction. From publishing Chinese academic papers that had been translated into English, the journal shifted to publishing original papers, which have not appeared in print anywhere before. This important reorientation allowed us to develop a close contact with scholars studying Chinese education around the world, and to publish their insights into Chinese education in a timely manner. Prior to publication, every paper goes through a rigorous peer review process and the subsequent decisions are made with adequate communication and discussion. In working with scholars who are knowledgeable about Chinese education, including our authors, readers, and reviewers, we have developed a solid professional relationship and a valuable friendship, for which we always feel grateful. Owing to their suggestions, we have been able to introduce various initiatives for the purpose of bettering this journal.

Three years on from this transformation, we have already published 84 academic papers, of which 32 were authored by the Chinese Mainland scholars, and 52 were written by overseas scholars. We have published eight special issues over this period, including: "A move towards the integration between education and technology," "Gender issues in higher education," "Research on work and learning," "China's move to mass higher education," "English immersion in China," "Educational leadership in China," "Early childhood education," "Education and cultural diversity in China's society" and "Education and cross cultural dialogue." We have involved 140 reviewers from China and abroad in the peer review process, who have gained a greater understanding of China and Chinese education while offering crucial assistance in maintaining the high academic standards of this journal.

Frontiers of Education in China is now planning to introduce two new 
sections-book reviews and research reports. We plan to publish essays that review new and recent books on Chinese education, comparative education, and Asian education, which are published in the Chinese or English languages. In this way, the readers of our journal will have the opportunity to become familiar with major contemporary works that relate to Chinese education and are being published worldwide. At the same time, the unique perspectives of our book reviewers may bring a critical edge to the discussion of these new works of scholarship. As for our plan to publish research reports that may reflect more a stage in the process of a research project than a conclusive scholarly analysis, we believe this type of publication will make available the most up-to-date information on important developments in Chinese education. Making current research findings public as quickly as possible should encourage the growth of richer investigation, thought, and analysis.

At the dawn of the Chinese lunar year of the snake, the editors and staff of this journal wish our readers the best in 2013. We sincerely welcome your continuing involvement in Frontiers of Education in China, which is our common endeavor to explore the global significance of Chinese education and thereby enrich global educational theory. 